\title{
Comparison of inhaled atropine sulphate and atropine methonitrate
}

\author{
CHRISTOPHER J ALLEN AND ALASTAIR H CAMPBELL \\ From the Division of Thoracic Medicine, Repatriation General Hospital, Heidelberg, Australia
}

ABSTRACT The bronchodilator potencies of inhaled atropine sulphate and atropine methonitrate $\frac{\vec{N}}{0}$ have been compared either alone or in combination with fenoterol in a group of adult asthmatic N patients. A cumulative dose response study showed that $2 \mathrm{mg}$ of atropine sulphate produced near 을 maximum bronchodilatation. A larger dose of $4 \mathrm{mg}$ was used in comparing the potency of this drug $\vec{\nabla}$ with $2 \mathrm{mg}$ of atropine methonitrate, a dose previously shown to produce optimum bronchodilatation. ${ }^{D}$ In a randomised double-blind fashion atropine methonitrate $(2 \mathrm{mg})$, atropine sulphate $(4 \mathrm{mg}), \stackrel{\Phi}{3}$ fenoterol $(400 \mu \mathrm{g})$, a combination of atropine methonitrate with fenoterol, a combination of ${ }_{\mathbb{D}}^{3}$ atropine sulphate with fenoterol, and two placebos were administered by inhalation on separate days to eight stable adult asthmatics. Measurements of $\mathrm{FEV}_{1}$ were made before administration of $\overrightarrow{\mathscr{Q}}^{\vec{D}}$ the drugs and at 20 minutes, one, two, four, and six hours afterwards. The two atropine drugs. produced a similar peak effect but the bronchodilatation after atropine methonitrate was more prolonged. In combination the bronchodilatation achieved with both atropine drugs and fenoterol was greater than with either atropine or fenoterol alone, confirming that atropine and an adrenergic drug can have an additive effect. The response with atropine methonitrate and fenoterol showed a $\frac{\odot}{\Phi}$ significant increase in the $\mathrm{FEV}_{1}$ for six hours whereas with atropine sulphate and fenoterol the $\stackrel{\varrho}{\Rightarrow}$ increase of $\mathrm{FEV}_{1}$ was significantly greater than the placebo for only four hours. It was concluded $\underset{P}{\mathcal{O}}$ that the atropine drugs produce useful bronchodilatation either alone or in combination with an $\frac{3}{\vec{D}}$ adrenergic agent. Of the two atropine drugs, the methonitrate appears to be superior to the sulphate as an inhaled bronchodilator in adult asthmatics.

The anticholinergic drugs atropine sulphate and atropine methonitrate are effective bronchodilators. Moreover, in adults with chronic asthma, optimum doses of atropine methonitrate together with salbutamol produce significantly greater and more lasting bronchodilatation than either drug alone. ${ }^{1}$ Cavanaugh and Cooper ${ }^{2}$ have reported that provided an adequate dose is used, atropine sulphate by inhalation is a very effective bronchodilator in asthmatic children, but they did not detect any additive effect when isoprenaline was administered concurrently.

The aim of the present study has been to compare the effectiveness of atropine methonitrate with that of atropine sulphate either alone or in combination with the long-acting adrenergic agent, fenoterol. Optimal doses of the atropine drugs were compared. The dose of atropine methonitrate producing

Address for reprint requests: Dr AH Campbell, Repatriation General Hospital, Heidelberg 3077, Australia. maximum bronchodilatation had been determined $\frac{0}{3}$ previously. ${ }^{1}$ The optimum dose of atropine sulphate was determined as part of this investigation by examining its dose-response characteristics.

\section{Methods}

Thirteen men aged 45-71 years (mean 62 yr) agreed to enter the study. All had features of asthma but were stable when studied. Ten had positive skin 0 tests to multiple allergens, nine fulfilled the MRCW criteria for chronic bronchitis, and 10 were taking oral or inhaled steroids or both when studied.

\section{ATROPINE SULPHATE DOSE-RESPONSE STUDY}

To examine the dose-response of atropine sulphate, eight of the patients were studied as outpatients $\frac{0}{\widetilde{D}}$ while their asthma was stable. Bronchodilators were withheld for at least nine hours before any test. $\stackrel{\unrhd}{\square}$ Steroids were continued unchanged.

The technique used was similar to that described 
by Pierce et $a^{1}$ for atropine methonitrate. The atropine sulphate was administered as either $1 \%$ or $0.5 \%$ aqueous solution inhaled from a Bennett twin nebuliser, powered by air, at a flow rate of eight litres per minute for three seconds, during each full inspiration from close to residual volume. Ten such inhalations delivered $2 \mathrm{mg}$ with the $1 \%$ solution and $1 \mathrm{mg}$ with the $0.5 \%$ solution. Baseline measurements of $\mathrm{FEV}_{1}$ were made. The patient then inhaled $2 \mathrm{mg}$ of atropine sulphate. After 40 minutes, further measurements of $\mathrm{FEV}_{1}$ were made and the patient then inhaled a further $1 \mathrm{mg}$ of atropine sulphate. After a further 40 minutes the $\mathrm{FEV}_{1}$ was measured again and further $1 \mathrm{mg}$ of atropine sulphate inhaled. Final measurements of $F V_{1}$ were made 40 minutes after the third dose. For each time interval the best of three measurements of $\mathrm{FEV}_{1}$ was taken and corrected to BTPS. With this technique the cumulative dose was $2 \mathrm{mg}, 3 \mathrm{mg}$, and $4 \mathrm{mg}$. Measurements of $\mathrm{FEV}_{1}$ were made on a Godart Spirometer and significance of the results analysed using Student's $t$ test.

\section{DRUG COMPARISON STUDY}

For the drug comparison studies, eight of the patients were admitted to hospital in a stable state. Bronchodilators were withheld as in the first study.

In a randomised, double-blind fashion on six week days (consecutive where possible), the eight patients were given $2 \mathrm{mg}$ atropine methonitrate, $4 \mathrm{mg}$ atropine sulphate, $400 \mu \mathrm{g}$ fenoterol, the combination of atropine methonitrate and fenoterol, the combination of atropine sulphate and fenoterol, or two placebos. Each study started at about $0900 \mathrm{~m}$ and followed an identical procedure. A wet aerosol was given followed by two puffs from a pressurised metered dose inhaler. In randomised order the wet aerosol contained a $1 \%$ aqueous solution of atropine methonitrate, a $2 \%$ aqueous solution of atropine sulphate, or water as placebo. To avoid contamination each wet aerosol was given from separate identical containers via a Bennett twin nebuliser as described in the doseresponse study. Fenoterol was delivered from a metered dose inhaler ( $200 \mu \mathrm{g}$ per puff). An identical inhaler containing only the propellant gases was used as the pressurised aerosol placebo.

The significance of the results was determined by analysis of variance. The baseline FEV 1 was added as a covariate to exclude its influence upon subsequent changes after the drugs.

\section{Results}

ATROPINE SULPHATE DOSE-RESPONSE STUDY The results of the atropine sulphate dose-response

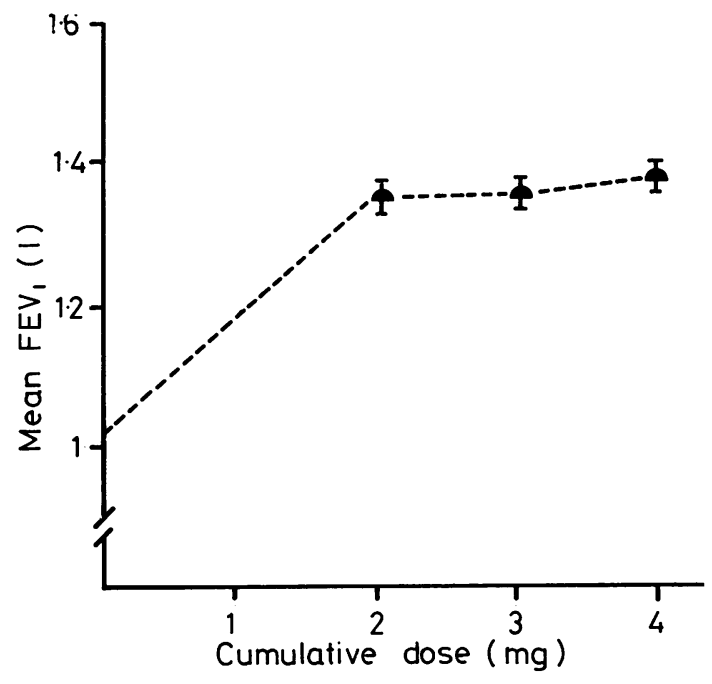

Fig 1 Mean increase of FEV 1 SEM after cumulative doses of atropine sulphate $(n=8)$.

study are shown in fig 1 . After $2 \mathrm{mg}$ there was a statistically significant rise in $\mathrm{FEV}_{1}$ of $32 \%$ compared to baseline $\mathrm{FEV}_{1}$. This approximated the maximum peak response, as with cumulative doses of $3 \mathrm{mg}$ and $4 \mathrm{mg}$ there were further rises of only $1 \%$ and $3 \%$ in $\mathrm{FEV}_{1}$ compared to baseline. These increases in $\mathrm{FEV}_{1}$ were not statistically greater than after $2 \mathrm{mg}$ of atropine sulphate.

Six patients complained of dryness of the mouth or throat. One had dizziness and another had blurred vision.

\section{DRUG COMPARISON STUDY}

Used singly, both atropine drugs and fenoteral produced a significant increase in $\mathrm{FEV}_{1}$ compared with the placebo ( $p<0.05$, fig 2). This was found up to one hour for fenoterol, two hours for atropine sulphate, and six hours for atropine methonitrate. Atropine methonitrate produced significantly higher changes in $\mathrm{FEV}_{1}(\mathrm{p}<0.05)$ than atropine sulphate at four and six hours, and than fenoterol at six hours. The mean of baseline $\mathrm{FEV}_{1}$ values, the range of these, and the standard error of mean (SEM) values for each drug and time are shown in the table.

Atropine methonitrate with fenoterol produced a similar degree of bronchodilatation as atropine sulphate with fenoterol (fig 3). Compared with the placebo this lasted for six hours for the former combination, whereas a statistically significant increase of the $\mathrm{FEV}_{1}$ was obtained for only four hours with the atropine sulphate/fenoterol combination.

The combination of atropine sulphate with 


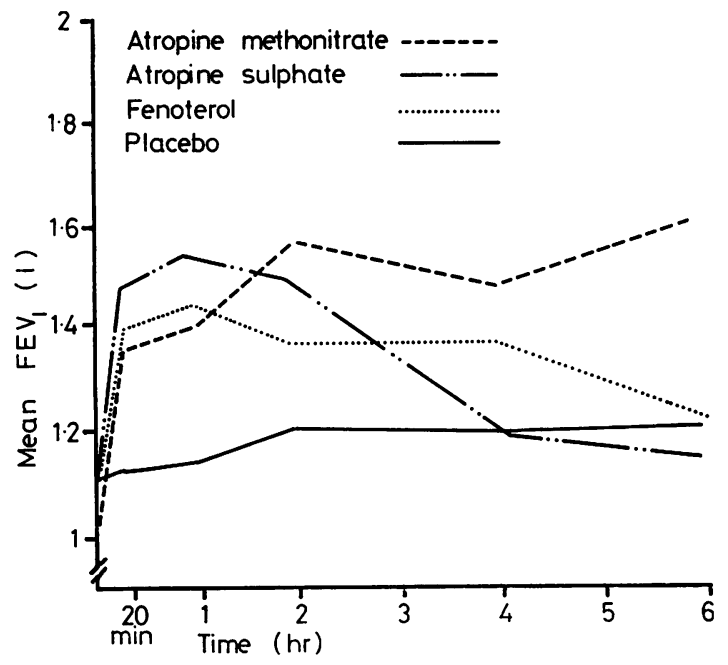

Fig 2 Mean $F E V_{1}$ after administration of atropine methonitrate $2 \mathrm{mg}$, atropine sulphate $4 \mathrm{mg}$, fenoterol $400 \mu \mathrm{g}$, or placebo. Values of SEM as in table.

fenoterol produced a significantly higher increase in $\mathrm{FEV}_{1}$ than atropine sulphate alone at 20 minutes, two hours, four hours, and six hours, and higher than fenoterol alone at 20 minutes, one hour, two hours, and four hours.

The combination of atropine methonitrate with fenoterol produced a significantly higher $\mathrm{FEV}_{1}$ than fenoterol alone at all times, and after atropine methonitrate alone at all times except at six hours.

Fenoterol was well tolerated without any sideeffects, as were placebos. Atropine sulphate produced dryness of the mouth in three patients and giddiness in three. Three patients experienced dryness of the mouth with atropine methonitrate. Symptoms were less common with the combination of drugs.

\section{Discussion}

Although our study did not determine the lowest

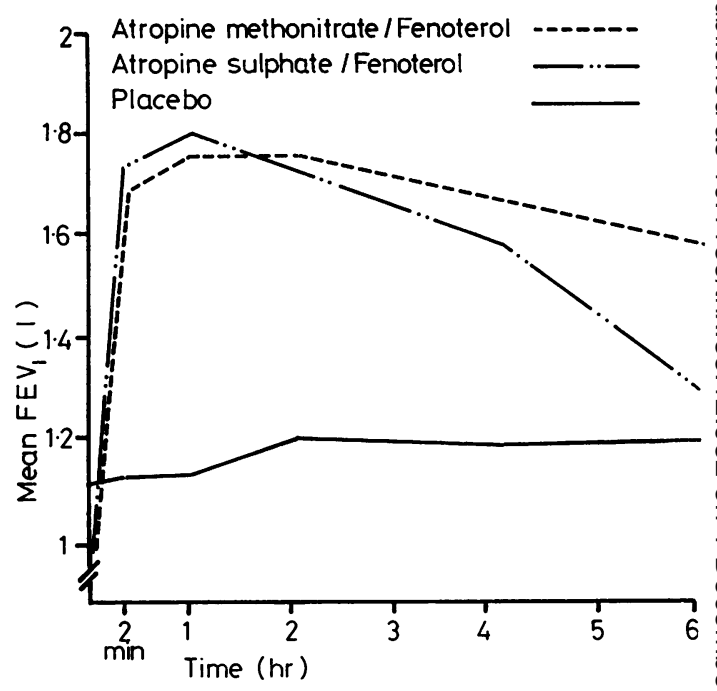

Fig 3 Mean FEV $V_{1}$ after administration of combination of atropine methonitrate $2 \mathrm{mg}$ plus fenoterol $400 \mu \mathrm{g}$ or of atropine sulphate $4 \mathrm{mg}$ plus fenoterol $400 \mu \mathrm{g}$, compared with placebo.

possible dose of atropine sulphate which will produce maximum bronchodilatation, it did show that as a wet aerosol by inhalation a dose of $2 \mathrm{mg} \stackrel{\mathrm{D}}{\mathrm{Q}}$ is adequate, and a dose of $4 \mathrm{mg}$ is more than adequate for this purpose. Consequently the failure of a dose $\overline{0}$ of $4 \mathrm{mg}$ of atropine sulphate to produce bronchodilatation as prolonged as that produced by a dose of $2 \mathrm{mg}$ atropine methonitrate cannot be attributed to an inadequate dose. Instead, it confirms that atropine sulphate is less potent than atropine methonitrate when both are administered by inhalation.

The combination of atropine sulphate with fenoterol produced significantly greater broncho- $\frac{1}{3}$ dilatation than either atropine sulphate or fenoterol alone. This result differs from that of Cavanaugh and Cooper ${ }^{2}$ who did not obtain any additive effect $\frac{7}{2}$ with isoprenaline and atropine sulphate in children. This may be because of the different type of patient $/$ N or the use of a short-acting adrenergic agent, as an $N$

Table Values of $F E V_{1}$ for each drug and time

\begin{tabular}{|c|c|c|c|c|c|c|c|c|}
\hline & \multirow{2}{*}{$\begin{array}{l}\text { Mean baseline FEV } \\
(l)\end{array}$} & \multirow{2}{*}{$\begin{array}{l}\text { Range baseline } F E V_{1} \\
(l)\end{array}$} & \multicolumn{6}{|c|}{ Standard error of mean } \\
\hline & & & Baseline & $\begin{array}{l}20 \\
\min \end{array}$ & $\begin{array}{l}1 \\
h r\end{array}$ & $\begin{array}{l}2 \\
h r\end{array}$ & $\begin{array}{l}4 \\
h r\end{array}$ & $\begin{array}{l}6 \\
h r\end{array}$ \\
\hline $\begin{array}{l}\text { Atropine methonitrate } \\
\text { Atropine sulphate } \\
\text { Fenoterol } \\
\text { Atropine methonitrate + fenoterol } \\
\text { Atropine sulphate + fenoterol } \\
\text { Placebo }\end{array}$ & $\begin{array}{l}1 \cdot 05 \\
1 \cdot 04 \\
1 \cdot 07 \\
1 \cdot 00 \\
1 \cdot 05 \\
1 \cdot 11\end{array}$ & $\begin{array}{l}0.64-1 \cdot 67 \\
0.50-1 \cdot 69 \\
0.58-1 \cdot 76 \\
0.65-1 \cdot 54 \\
0.55-1 \cdot 52 \\
0.74-1 \cdot 68\end{array}$ & $\begin{array}{l}0 \cdot 125 \\
0 \cdot 131 \\
0 \cdot 146 \\
0 \cdot 121 \\
0 \cdot 115 \\
0 \cdot 103\end{array}$ & $\begin{array}{l}0 \cdot 167 \\
0 \cdot 172 \\
0 \cdot 170 \\
0 \cdot 154 \\
0 \cdot 186 \\
0 \cdot 107\end{array}$ & $\begin{array}{l}0 \cdot 148 \\
0 \cdot 165 \\
0 \cdot 163 \\
0 \cdot 181 \\
0 \cdot 169 \\
0 \cdot 111\end{array}$ & $\begin{array}{l}0 \cdot 185 \\
0 \cdot 174 \\
0 \cdot 147 \\
0 \cdot 159 \\
0 \cdot 185 \\
0 \cdot 218\end{array}$ & $\begin{array}{l}0 \cdot 162 \\
0 \cdot 133 \\
0 \cdot 163 \\
0 \cdot 113 \\
0 \cdot 153 \\
0 \cdot 099\end{array}$ & $\begin{array}{l}0 \cdot 173 \\
0 \cdot 127 \\
0 \cdot 153 \\
0 \cdot 107 \\
0 \cdot 115 \\
0 \cdot 121\end{array}$ \\
\hline
\end{tabular}


additive effect has been demonstrated with atropine methonitrate and salbutamol, using optimum doses of each in adult asthmatic patients. ${ }^{1}$ Similarly atropine methonitrate with fenoterol produced greater bronchodilatation than both fenoterol and atropine methonitrate alone in the present study.

Our dose-response study ensured that we had an adequate dose of atropine sulphate, and the studies of Shenfield and Paterson ${ }^{3}$ suggest that the dose of fenoterol used in our study was optimum. Hence, the additive effect demonstrated is unlikely to be the result of suboptimal doses of either drug. It may be related to differences in the pharmacological action of each drug or to differences in receptor sites within the airways. Ingram et $a^{4}$ have reported that atropine has a relatively greater effect than adrenergic stimulants upon larger airways of normal subjects. However, despite this differentiation, the combined effects of atropine sulphate and isoprenaline were not found to be additive in normal subjects when the drugs were combined. Pharmacological differences between the drugs may be more relevant. It has been shown that beta-adrenergic drugs are functional antagonists of cholinomimetics, such as methacholine, whereas atropine is a competitive antagonist. ${ }^{5}$ Functional antagonists act through a separate receptor system without changing the receptors of the spasmogen, whereas competitive antagonists inhibit the spasmogen receptors. Because of this difference in action, the effects of atropine and of adrenergic drugs can be additive. This has been demonstrated in the isolated trachea of animals. ${ }^{5}$ This additive effect using atropine is likely to occur only when bronchoconstriction is through the cholinergic pathway. When spasmogens such as histamine produce bronchocon- striction through other receptors, atropine is unlikely to be an effective bronchodilator. The patients in the present investigation may have been particularly responsive to anticholinergic drugs. They were studied when relatively stable and all those in the drug comparison trial were receiving corticosteroids. Patients with these characteristics are more responsive to anticholinergic drugs than other asthmatics. ${ }^{6}$ We have shown that in such patients, both atropine methonitrate and atropine sulphate alone or with fenoterol, produce useful bronchodilatation by inhalation and that the methonitrate is superior to the sulphate.

\section{References}

1 Pierce RJ, Allen CJ, Campbell AH. A comparative study of atropine methonitrate, salbutamol and their combination in airways obstruction. Thorax 1979; 34:45-50.

2 Cavanaugh MJ, Cooper DM. Inhaled atropine sulphate: dose response characteristics. Am Rev Respir Dis 1976; 114:517-24.

3 Shenfield G, Paterson J. Clinical assessment of bronchodilator drugs delivered by aerosol. Thorax 1973; $28: 124-8$.

4 Ingram RH, Wellman JJ, McFadden ER, Mead J. Relative contributions of large and small airways to flow limitation in normal subjects before and after atropine and isoprenaline. $J$ Clin Invest 1977; 59: 696-703.

5 Offermeier J, Van Den Brink FG. The antagonism between cholinomimetic agonists and beta adrenoreceptor stimulants. The differentiation between function and metaffinoid antagonism. Eur $J$ Pharmacol 1974; $27: 206-13$.

6 Altounyan REC. Variation of drug action on airway obstruction in man. Thorax 1964; 19:406-15. 